\section{The Genetic Basis of Common Diseases, second edition}

Richard A King, Jerome I Rotter, Arno G Motulsky (eds.) Oxford University Press, Oxford, 2002

European Journal of Human Genetics (2004) 12, 337. doi:10.1038/sj.ejhg.5201131

Published online 24 December 2003

The first years I taught medical students Human Genetics, I often went back to Vogel and Motulsky's monumental book: Human Genetics Problems and Approaches, 3rd edition, whenever I wanted something to be understood in a more thorough manner than what the standard genetic text books for medical students aims at.

The book The Genetic Basis of Common Diseases where Arno Motulsky is also one of the editors gives you exactly the same impression of being a really thorough piece of work; yes, an almost monumental book.

In the 10 years that have gone by since the first edition of this book appeared, the search for genes underlying common diseases has become one of the really active areas of biomedical research, which is supported by government and nonprofit foundations as well as by industries.

The goal of the book is to convey current knowledge in the understanding of genetics of specific illnesses, but at the same time to provide the reader with the necessary background to understand why solving the genetic basis of complex disorder is slower than in Mendelian diseases.

The book comprises 55 chapters divided up in 11 parts.

The first six chapters comprise the part called Approaches in which chapter one is on human genetics and application of genetics in common diseases. I had the expectation that in this chapter bi- or three allelic inheritances would have been mentioned, but unfortunately it was not. It is not mentioned anywhere in the book. There is furthermore a chapter on molecular genetics of common disease and this is also a thorough and nice chapter, but now and then there are some problems in, for example, the fact that terms that might be everyday nomenclature to molecular geneticists but not to clinicians and epidemiologists are presented but not explained. One example is household genes.

The same problem arises in the chapter on genetic epidemiologic methods in which for example terms like dominance and epistatic effects are mentioned but never explained. In this chapter, it would have been nice to see a more thorough description of twin studies, but on the other hand this might just be me reflecting the tendency we all have to nurse our own little darlings.
Chapter four on evolution of human genetic diseases is interesting and the strength of both this chapter and the chapter on genetic epidemiologic methods is that neither uses complicated mathematical language to explain the concepts. This part of the book end with one chapter on animal models of complex genetic diseases and one on genetic counselling, and after having read this the epidemiologist or clinician is expected to be quite prepared to go on with the other chapters in which specific diseases are dealt with.

The book describes almost all complex diseases that one can think of and ends up with the part 10 with other common problems in which ageing and longevity, mitochondrial defects and constitutional chromosome disorders are described.

The 11th part of the book deals with therapy, genetic consequences of modern therapeutics and pharmacogenetics.

Most of the chapters on diseases are built in the same way that makes it very easy to use the book. Most chapters start with disease definitions and classification problems if any, then a piece of clinical presentation, general genetic and epidemiological evidence about the disease, pathophysiology and then parts on gene identification.

Many of the chapters end up with a summary of progress and some reflections on clinical applications, risk assessment and genetic counselling.

Here and there one wonders about the decisions on what evidence to include; for example, in the chapter of type 1 diabetes in which there are a substantial part of infectious agents but no mention of the studies indicating that for example enterovirus infections in the mother during the pregnancy might render offspring more liable to type 1 diabetes.

Also in the chapter of common skin disorders, it is surprising to find out that vitiligo and male pattern baldness are described, but a very common skin disorder like hand exema, which at least in Denmark has prevalence of over $5 \%$, is not included at all.

These examples are few, although, and the overall impression of the book is a very thorough and in many ways useful book, perhaps especially for epidemiologists with specific interest in genetics and diseases, but without detailed clinical and genetic knowledge. Thus, the goal of the authors seems to be fulfilled, but one cannot help worrying that especially the genetic information in the book runs the risk of being outdated very quickly.

Kirsten Ohm Kyvik

University of Southen Denmark, Epidemiologi, Sønder Boulevard 23A, Odense, 5000 Denmark 